\title{
Congenital nephrotic syndrome
}

\author{
Hannu Jalanko
}

Received: 19 June 2007 /Revised: 3 September 2007 / Accepted: 10 September 2007 / Published online: 30 October 2007

(C) IPNA 2007

\begin{abstract}
Congenital nephrotic syndrome (CNS) is a rare kidney disorder characterized by heavy proteinuria, hypoproteinemia, and edema starting soon after birth. The majority of cases are caused by genetic defects in the components of the glomerular filtration barrier, especially nephrin and podocin. CNS may also be a part of a more generalized syndrome or caused by a perinatal infection. Immunosuppressive medication is not helpful in the genetic forms of CNS, and kidney transplantation is the only curative therapy. Before the operation, management of these infants largely depends on the magnitude of proteinuria. In severe cases, daily albumin infusions are required to prevent life-threatening edema. The therapy also includes hypercaloric diet, thyroxin and mineral substitution, prevention of thrombotic episodes, and prompt management of infectious complications. The outcome of CNS patients without major extrarenal manifestations is comparable with other patient groups after kidney transplantation.
\end{abstract}

Keywords Proteinuria $\cdot$ Nephrotic syndrome $\cdot$ Nephrin . Podocin $\cdot$ Podocyte $\cdot$ Kidney transplantation

\section{Introduction}

Congenital nephrotic syndrome (CNS) is defined as heavy proteinuria starting within three months after birth. Nephrotic syndrome (NS) appearing later during the first year (4-12 months) is defined infantile, and NS manifesting

H. Jalanko $(\bowtie)$

Hospital for Children and Adolescents, University of Helsinki, Stenbackinkatu 11, Helsinki 00029 HYKS, Finland

e-mail: hannu.jalanko@hus.fi thereafter is called childhood NS [1,2]. These definitions have been used for decades in order to help the clinical diagnosis, although recent findings indicate that NS caused by a particular gene defect can manifest at various ages, questioning the rationale of the classification. Since the overall etiology, clinical features and management of CNS, however, are different from the more common forms of childhood NS, the terminology still seems warranted (Table 1).

\section{Glomerular filtration barrier}

The cardinal feature of CNS is the extensive leakage of plasma proteins into urine. In most cases, this is caused by mutations in genes encoding for structural or regulatory proteins of the kidney filtration barrier located in the glomerular capillary wall [3-5]. This filter is composed of three layers: fenestrated endothelium, glomerular basement membrane (GBM), and epithelial cell (podocyte) layer with distal foot processes and interposed slit diaphragms (SD) (Fig. 1). The barrier is an effective size- and chargeselective molecular sieve, and normally only water and small plasma solutes pass through it. The flux of albumin and larger plasma proteins is restricted by the GBM and especially $\mathrm{SD}$, so that the protein content of the ultrafiltrate (primary urine) reaching the Bowman space is very low. The GBM's role in glomerular permselectivity has been debated recently, but it is now known that proteinuria can be caused by a primary defect in either SD or GBM.

The GBM is a well-known protein network formed by type IV collagen, laminin, nidogen, and negatively charged proteoglycans. On the other hand, the precise molecular structure of the SD is still unresolved. Recently identified podocyte proteins, such as nephrin, Neph1, Neph2, FAT1, 
Table 1 The etiology of congenital nephrotic syndrome (CNS)

Primary CNS
Nephrin gene mutations [NPHS1, Finnish type of CNS (CNF)]
Podocin gene mutations (NPHS2)
WT1 gene mutations (Denys-Drash, isolated CNS)
LamB2 gene mutations (Pierson syndrome, isolated CNS)
PLCE1 gene mutations
LMX1B mutations (nail-patella syndrome)
LamB3 gene mutations (Herlitz junctional epidermolysis bullosa)
Mitochondrial myopathies
CNS with or without brain and other malformations (no gene defect
identified as yet)
Secondary CNS
Congenital syphilis
Toxoplasmosis, malaria
Cytomegalovirus, rubella, hepatitis B, HIV
Maternal systemic lupus erythematosus
Neonatal autoantibodies against neutral endopeptidase
Maternal steroid-chlorpheniramine treatment

FAT2, and dendrin probably form the backbone of SD [68]. These proteins associate with each other extracellularly and interact with the adapter proteins, such as podocin, CD2AP, ZO-1, CASK, and MAGI-1, localized in the cytosolic part of the podocyte. These connect SD with the actin cytoskeleton of the podocyte foot process and take part in signal transduction from the slit diaphragm area into podocyte [9]. Actin network and the interacting proteins, such as $\alpha$-actinin- 4 , are critical for maintenance of the complex structure of the podocyte. Interestingly, this molecular organization becomes disrupted in CNS and other proteinuric disorders, leading to effacement of podocyte foot processes.

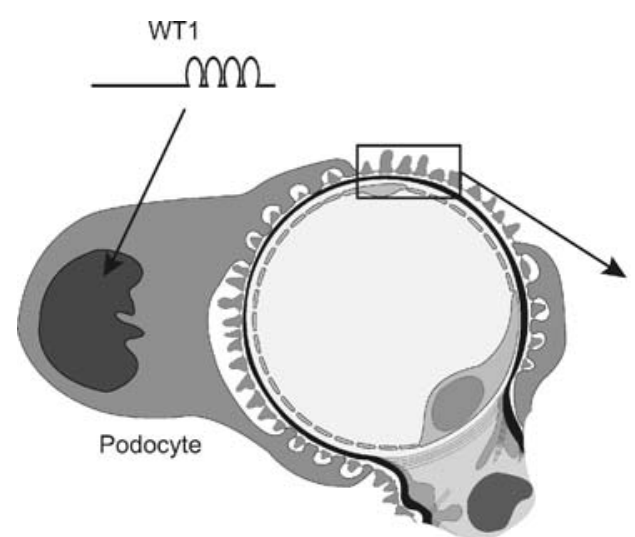

Fig. 1 Cross-section of a glomerular capillary (left) and electron microscopy image of a normal capillary wall (right). WT1 is a transcription factor important for podocyte function. Nephrin is a major component of the slit diaphragm $(S D)$ connecting podocyte foot

\section{Different forms of CNS}

Nephrin gene (NPHS1) mutations

Mutations in NPHS1 gene cause CNS, which was originally named as the Finnish type of CNS, or CNF [10]. Since CNF originally referred to a clinical entity (severe form of CNS), an abbreviation of NPHS1 (nephrotic syndrome type 1) was introduced to specify those cases known to be caused by NPHS1 mutations [10]. In practice, both terms are used for the same disorder. The incidence of NPHS1 is one in 8,000 live births in Finland, and about half of the published cases are Finns. Currently, close to 100 mutations in the NPHSI gene have been identified [11-13]. Most patients have individual mutations of different types, except in Finland, where two founder mutations (Fin-major and Fin-minor) are detected in almost all cases. NPHS1 codes for nephrin, which is a 1241-residue transmembrane adhesion protein of the immunoglobulin superfamily (Fig. 1). Nephrin is synthesized almost exclusively by glomerular podocytes and is a crucial component of the SD, as noted above.

Compared with many other genetic disorders, NPHS1 shows relatively little phenotypic variation [14]. Most of these children are born prematurely, with a birth weight ranging between 1,500 and $3,500 \mathrm{~g}$. The placental weight is over $25 \%$ of the newborn weight in practically all cases. Amniotic fluid may be meconium stained, but the infants do not usually have major respiratory problems. Importantly, NPHS1 infants do not have extrarenal malformations. On the other hand, minor functional disorders, such as muscular hypotonia and cardiac hypertrophy, are common during the nephrotic stage. Proteinuria begins in utero and is detectable in the first urine sample after birth. Microscopic hematuria and normal creatinine values during the first months are typical. Heavy protein loss (up to

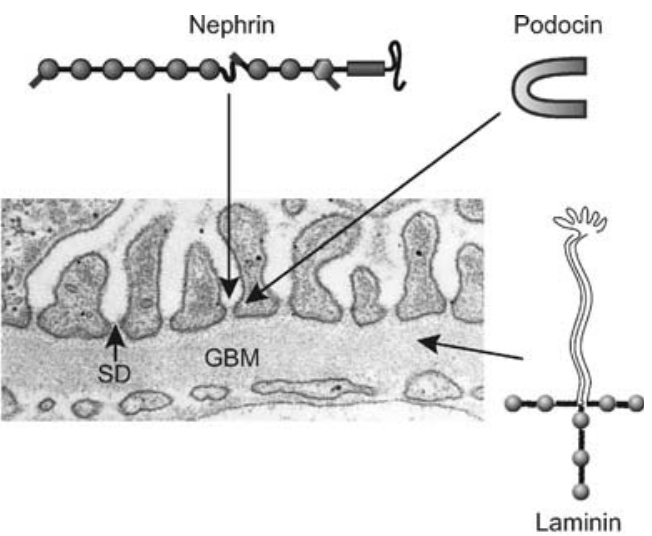

processes. Podocin is an adapter protein located intracellularly in the $\mathrm{SD}$ area. Laminin is a major structural protein of the glomerular basement membrane $(G B M)$. Genetic mutations in these proteins lead to congenital nephrotic syndrome 
$100 \mathrm{~g} / \mathrm{L}$ ) results in oliguria and severe edema if not treated. Hyperlipidemia is also present, as in other forms of NS.

The NPHS1 kidneys are large and in ultrasound scans cortical echogenicity is increased, and the corticomedullary border is indistinct. In renal histology, no single histological finding is pathognomonic for NPHS1. Expansion of glomerular mesangium and dilations in the proximal and distal tubules are the most characteristic findings. Interstitial fibrosis and inflammatory infiltrates, especially around the glomeruli, increase with time. Effacement of podocyte foot processes and disappearance of the filamentous image of SD are seen in electron microscopy [14].

Podocin gene (NPHS2) mutations

Mutations in the NPHS2 gene, encoding for a podocyte protein podocin, are a common cause of childhood (steroidresistant) NS, but they are also important in the development of CNS [11-16]. In a recent report, NPHS2 mutations accounted for half of the CNS cases in 80 European families, while $N P H S 1$ mutations were responsible for only one third of the cases [17]. The NPHS2 mutations have also been found in CNS patients from Japan and elsewhere. They are typically "severe", leading to nonfunctional podocin protein (often truncated). Since podocin is a podocyte-adapter protein required for proper targeting of nephrin into $\mathrm{SD}$, nephrin expression also may be distorted in CNS caused by NPHS2 mutations (Fig. 1) [18]. Coexistence of NPHS1 and NPHS2 mutations has been reported in CNS patients, but the clinical significance of this is not clear [11, 19].

No systematic analysis of clinical findings in CNS patients with NPHS2 mutations has been published. The severity of proteinuria and, thus, the clinical findings are more variable than in NPHS1 patients [16]. The kidney histology often, but not exclusively, shows focal and segmental glomerular sclerosis (FSGS). Patients develop end-stage renal disease (ESRD) at the age of a few years [17]. Podocin is only expressed in kidney glomerulus, and no major extrarenal manifestations are present. As is the case in NPHS1, minor cardiac problems have been reported.

\section{Other genetic forms}

Wilms' tumor suppressor gene (WT1) encodes for a transcription factor WT1, which plays a crucial role in the embryonic development of the kidney and genitalia (Fig. 1). It is abundantly expressed in podocytes and controls cellular functions, such as nephrin expression. Mutations in WT1 may cause several types of developmental syndromes (Denys-Drash, Frasier, and WAGR syndromes) manifesting in childhood [20-22]. WT1 mutations can also cause an isolated kidney disease, with NS appearing in the first 3 months of life [17, 23]. They account for a few percent of CNS cases. Patients may have moderate proteinuria, and renal biopsy most often reveals diffuse mesangial sclerosis (DMS) of glomeruli.

A new genetic entity comprising CNS and distinct ocular anomalies with microcoria as the leading clinical feature (Pierson syndrome) was described in 2004 [24]. The disorder is caused by mutations in the laminin- $\beta 2$ gene (LAMB2). Laminin- $\beta 2$ is a component of GBM, where it is crucial for the network structure and anchoring of GBM to podocyte foot processes (Fig. 1). Interestingly, this was the first clear evidence that genetic defects in the GBM components can cause CNS in humans. Later studies revealed that the spectrum of $L A M B 2$-associated disorders is broader than first suggested, and CNS patients without eye involvement have been described [25].

Galloway-Mowat syndrome (GMS) is characterized by NS with central nervous system anomalies, including microcephaly, psychomotor retardation, and brain anomalies [26]. Other extrarenal disorders, such as hiatus hernia, dysmorphic features, shortness, and diaphragmatic defects, have also been reported [2]. NS appears usually at the age of a few months (0-34 months), and kidney biopsy may show only minor changes [minor-change nephrotic syndrome (MCNS)], FSGS, or DMS. GMS is an autosomal recessive disorder, but the genetic $\operatorname{defect}(\mathrm{s})$ is still unknown. Podocytes resemble neuronal cells and share many structural proteins. Thus, genetic syndromes affecting both kidney and central nervous system are not surprising.

In addition to GMS, there are reports on other, unique, combinations of NS and extrarenal defects, including CNSassociated mitochondrial cytopathy [27], nail-patella syndrome [28], congenital disorder of glycosylation type I [29], Herlitz junctional epidermolysis bullosa [30], and CNS caused by mutations in the phospholipase $\mathrm{C}$ epsilon gene (PLCE1) [31].

\section{Nongenetic forms}

Genetic defects account for the great majority of CNS cases, but especially in developing countries, infections are a possible etiology. Congenital syphilis has long been known to cause nephritic or nephrotic syndrome in the newborn [32]. Proteinuria and hematuria are present, but severe NS is less common. Kidney biopsy shows membranous nephropathy. Antimicrobial therapy with penicillin is curative provided that irreversible renal lesions have not developed. Toxoplasmosis, congenital rubella, and hepatitis $\mathrm{B}$ virus infection may also cause CNS. HIV can also infect kidney (podocytes) and is associated with nephropathy, including NS. It usually appears in children older than 1 year, but affected infants have been reported. An association of neonatal cytomegalovirus infection (CMV) and CNS has 
also been reported [33]. CMV infection is common during the first weeks of life, and detection of this virus in an infant with NS does not exclude an underlining genetic defect. This should be searched especially if ganciclovir therapy is not helpful. In addition to infections, CNS has been associated with maternal systemic lupus erythematosus and more recently with neonatal alloimmunization against neutral endopeptidase present on podocytes [34].

\section{Diagnosis of CNS}

In severe forms of CNS, generalized edema, urinary protein $>20 \mathrm{~g} / \mathrm{L}$, and serum albumin level $<10 \mathrm{~g} / \mathrm{L}$ can be detected in the newborn period. The amount of proteinuria, however, varies in different entities, and the clinical signs may not be evident during the first weeks of life. Also, the true magnitude of proteinuria may be detectable only after partial correction of hypoproteinemia by albumin infusions. Small amounts of red blood cells and leucocytes are often present in urine. Serum creatinine and urea levels are variable. Renal function remains quite normal for the first months in NPHS1, but in other forms, kidney failure may develop faster. Blood pressure values can be low due to hypoproteinemia or elevated if renal failure is already present.

In newborns, the placental weight $>25 \%$ of birth weight is present in NPHS1 but may be seen in other forms of CNS [14]. The kidneys may be of normal size or larger than normal in ultrasound scanning, and the renal cortex is often hyperechogenic. Search for possible nonrenal malformations is important, especially since they may give clues to the etiologic diagnosis. These include genital abnormalities (WT1), eye defects (LAMB2), and neurological disorders (Mowat-Galloway). Cardiac evaluation often reveals ventricular hypertrophy but no structural defects.

Renal biopsy does not reveal the etiology of CNS. As pointed out, the genetic defects may cause several types of glomerular lesions, such as mesangial expansion, FSGS, MCNS, and DMS, and the findings overlap in different entities. Also, the nonglomerular findings, such as tubular dilatations and interstitial fibrosis and inflammation, can be seen in all forms of proteinuric diseases. Thus, the indications for renal biopsy are not quite clear. The knowledge of severity of glomerular sclerosis and interstitial fibrosis may help in the assessment of treatment strategies. On the other hand, the lesions are focal, and the biopsy findings may be misleading. If immunohistochemistry for nephrin and podocin is available, analysis of their expression in a biopsy sample is useful. Total lack of either protein speaks for a severe disorder not responding to antiproteinuric therapy.

Genetic analysis is the method of choice for precise CNS diagnosis. The knowledge of etiology helps in assessing management and prognosis, in follow-up for possible associated symptoms, and in genetic counseling of the family. Analysis of NPHS1 and NPHS2 mutations is warranted in all CNS patients. These analyses are commercially available in Athena Diagnostics (www.athenadiag nostics.com). If no mutations are detected in these genes or if clinical findings speak for mutations in WT1 or LAMB2 gene, analysis of these genes can be obtained at research laboratories.

Prenatal diagnosis in families with a known risk for CNS should be based on genetic testing whenever possible. The results can be obtained fast if the mutations are known in advance. In case of no family history or if the mutations in the affected child were not identified, prenatal genetic testing is a challenge, since sequencing the NPHS1 (29 exons) and NPHS2 (eight exons) genes is time consuming and usually not possible within the short time frame available. NPHS1 especially can still be suspected prenatally based on elevated alpha-fetoprotein (AFP) levels in maternal serum and amniotic fluid. If the AFP concentration in amniotic fluid is very high and the ultrasound examination does not reveal fetal anencephaly or other malformations, NPHS1 is a probable diagnosis. However, heterozygous fetal carriers of NPHS1 gene mutations may have temporarily elevated AFP levels in amniotic fluid and maternal serum, and repeated measurement of amniotic fluid AFP before the 20th week of pregnancy is recommended in cases with high AFP levels [35].

\section{CNS management}

In contrast to most cases of childhood NS, therapy with steroids or other immunosuppressive drugs does not bring CNS into remission. The goals of therapy during the first months are to control edema and possible uremia, prevent and treat complications such as infections and thromboses, and provide optimal nutrition so that the child grows and develops as normally as possible (Table 2). In most cases, kidney transplantation is the only curative treatment.

\section{Albumin infusions}

The magnitude of the protein losses into urine is crucial for therapeutic decision making. Heavy and constant proteinuria $(10-100 \mathrm{gr} / \mathrm{L})$ inevitably leads to life-threatening edema, protein malnutrition, reduced growth, and secondary complications. In these cases, protein substitution by parenteral albumin infusions is mandatory. Our practice in treating NPHS1 patients is to infuse $20 \%$ albumin solution together with a bolus of intravenous furosemide $(0.5 \mathrm{mg} / \mathrm{kg})$ using central venous catheters. The substitution is first divided into three 2 -h infusions (starting dose $1-5 \mathrm{ml} / \mathrm{kg}$ per 
Table 2 CNS management of infants with heavy proteinuria

Protein substitution parenterally

$20 \%$ albumin infusions (3-4 g/kg per day of albumin)

Nutrition

Hypercaloric diet (130 kcal/kg per day)

Protein supplementation ( $4 \mathrm{~g} / \mathrm{kg}$ per day)

Lipid supplementation (rapeseed/sun flower oil)

$\mathrm{A}, \mathrm{D}, \mathrm{E}$ and water soluble vitamins

Calcium and magnesium supplementation

Medication

Antiproteinuric drugs (ACE-inhibitor, indomethacin)

Thyroxin supplementation

Anticoagulation (warfarin, aspirin, ATIII-infusion)

Parenteral antibiotics when bacterial infection suspected

infusion) and after a few weeks given as one 6-h infusion during the night (up to $15-20 \mathrm{ml} / \mathrm{kg}$ each night; $3-4 \mathrm{~g} / \mathrm{kg}$ of albumin). This substitution corrects hypoproteinemia only temporarily, but the patients do not have substantial edema.

\section{Medications}

A reduction in the protein excretion using angiotensinconverting enzyme (ACE) inhibitors and indomethacin may be obtained in some infants with CNS [36]. Patients with severe NPHS1 or NPHS2 mutations inhibiting nephrin and podocin expression (stop codons, deletions, missense mutations) do not respond to this therapy, but in other cases, treatment with "antiproteinuric" medication is worth trying.

Due to the protein excretion, patients with NS often have low levels of serum thyroid-binding globulin and thyroxine. Thyroid-stimulating hormone (TSH) may be normal in the beginning but typically increases during the first months. Thus, thyroxine substitution is recommended in CNS patients. The medication can be started with 6.25-12.5 $\mu \mathrm{g} /$ day, and the dose can be adjusted according to $\mathrm{TSH}$ levels. Urinary protein losses result in imbalance of plasma coagulation factor levels, contributing to hypercoagubility and risk for thromboses. Thus, the use of aspirin and dipyridamole therapy has been recommended. Finnish NPHS1 patients are successfully treated with sodium warfarin from 3-4 weeks of age. Before surgical or vascular procedures, warfarin is stopped, and antithrombin III $(50 \mathrm{IU} / \mathrm{kg})$ is given to temporarily correct the deficiency.

Because of urinary losses of gamma globulin and complement factors and the use of indwelling catheters, nephrotic infants are prone to bacterial infections. Prophylactic use of antibiotics has been recommended, but in our experience, it is not helpful and only induces resistant bacterial strains. Similarly, prophylactic use of immunoglobulin infusion does not reduce the incidence of bacterial infections. On the other hand, a high degree of suspicion for septic infections is warranted. The symptoms are often vague and masked by signs of focal infections occurring at the same time. Parenteral antibiotic therapy should be started promptly on suspicion and should cover the major hospital strains of bacteria. Intravenous immunoglobulin is used along with the antibiotics in some centers. Response to treatment even in septic infection is usually excellent.

\section{Nutrition}

Infants with severe CNS have traditionally been treated with a high-energy (130 kcal/kg per day) and a high-protein (3-4 g/kg per day) diet. Breast milk and milk formulas are first used, and the excess protein is given as a casein-based protein product. Glucose polymers are given to increase energy intake, and a mixture of rapeseed and sunflower oil is given to balance lipid levels [2]. The children also receive vitamin $\mathrm{D}_{2}$ (400 IU/day), which is changed to alpha-calcidiol when an increase of parathyroid hormone level is noticed. Multivitamin preparations are given according to the recommended dietary allowances for healthy children of the same age. Supplementary magnesium (50 mg/day) and calcium (500-1,000 mg/day) are also given to keep serum levels within the normal range. Daily water intake is $100-130 \mathrm{~mL} / \mathrm{kg}$. Most patients need a nasogastric tube to guarantee their energy intake.

\section{Nephrectomy}

Some centers have a routine of performing unilateral nephrectomy to reduce protein losses [37]. This may decrease the frequency of the albumin infusions and help in the everyday management, so that renal transplantation can be postponed to an older age. Another approach is to perform an early bilateral nephrectomy and start peritoneal dialysis to avoid the complications encountered during the nephrotic stage. Our practice in treating NPHS1 patients is to perform bilateral nephrectomy when the child weighs about $7 \mathrm{~kg}$ and start peritoneal dialysis, which allows the infant stay at home. Renal transplantation is then performed a few months later when the child weighs more than $9 \mathrm{~kg}$ and the extraperitoneal placement of the graft is possible. The third possibility is to perform an early, preemptive renal transplantation with an intraperitoneal placement of the kidney graft. In this case, the nephrotic kidneys are removed at the same operation.

\section{Kidney transplantation}

Renal transplantation has become an established mode of therapy for most children with CNS. The fact that CNS children are often transplanted at 1-2 years of age using 
adult-size kidneys may sometimes be surgically demanding and increase the risk for thrombotic and ureteral complications compared with older recipients. Postoperatively, abundant hydration of the recipient $\left(3,000 \mathrm{ml} / \mathrm{m}^{2}\right)$ is necessary to maintain optimum aortic and renal artery blood flow and avoid low-flow states that could damage the graft [38]. The use of immunosuppressive medication should be balanced in order to prevent rejection episodes, which may be clinically subtle, and on the other hand, avoid the many side effects associated with these drugs. Recurrence of NS in the graft is rare but has occurred in some NPHS1 children who developed antinephrin antibodies after transplantation. Treatment of the recurrence with cyclophosphamide and plasmapheresis often leads to remission [39].

Overall, the results of kidney transplantation in CNS are quite good and similar to those obtained in other etiologies. Patient survival at 5 years is over $90 \%$ and graft survival over $80 \%$ in registry databases and in single centers [40, 41]. Chronic allograft nephropathy, however, is a major problem also in these patients, and a second transplantation is inevitable when the patients become young adults.

\section{Conclusions}

During the past few years, our knowledge on the genetic and molecular basis of CNS has greatly increased. Podocyte proteins play an important role in glomerular sieving, and mutations in genes encoding for nephrin, podocin, WT1 and laminin $\beta 2$ account for most cases of CNS. It is to be expected that more genetic defects will be found in CNS patients in the near future. Also, management of these infants has improved so that the outcome of CNS patients is very similar to other pediatric kidney patients requiring renal transplantation.

Acknowledgements This work was supported by grants from the Academy of Finland, the Sigrid Juselius Foundation, the Pediatric Research Foundation, the Päivikki and Sakari Sohlberg Foundation, and the Helsinki University Central Hospital Research Fund.

Questions (Answers appear following the reference list)

1. The cardinal findings in CNS are:

a. Heavy proteinuria, high serum creatinine, and low serum cholesterol

b. Heavy proteinuria, low serum albumin, and generalized edema c. Macroscopic hematuria, heavy proteinuria, high blood pressure values

2. The two most important structures preventing proteinuria in the kidney are:

a. Glomerular endothelial cells and basement membrane

b. Glomerular endothelial and epithelial cells

c. Podocyte slit diaphragm and glomerular basement membrane

3. The two most important genes associated with CNS are:
a. Nephrin (NPHS1) and podocin (NPHS2) genes
b. WTI and $L A M B 2$ genes
c. $C D 2 A P$ and $N E P H 1$ genes

4. CNS infants with heavy proteinuria have a risk for:
a. Bleeding episodes and hypertensive crisis
b. Thrombotic and septic episodes
c. Hyperthyroidism and hypermagnesemia

5. The effective treatment in most cases of CNS is:
a. Prednisone and other immunosuppressants
b. Calcium blockers and indomethacin
c. Renal transplantation

\section{References}

1. Habib R (1993) Nephrotic syndrome in the 1st year of life. Pediatr Nephrol 7:347-353

2. Holmberg C, Tryggvason K, Kestila M, Jalanko H (2004) Congenital nephrotic syndrome. In: Avner E, Harmon WE, Niaudet $\mathrm{P}$ (eds) Pediatric nephrology, 5th edn. Lippincott Williams \& Wilkins, Baltimore, pp 503-516

3. Jalanko H (2003) Pathogenesis of proteinuria: Lessons learned from nephrin and podocin. Pediatr Nephrol 18:487-491

4. Niaudet P (2004) Genetic forms of nephrotic syndrome. Pediatr Nephrol 19:1313-1318

5. Tryggvason K, Patrakka J, Wartiovaara J (2006) Hereditary proteinuria syndromes and mechanisms of proteinuria. $\mathrm{N}$ Engl $\mathrm{J}$ Med 354:1387-1401

6. Ruotsalainen V, Lungberg P, Wartiovaara J, Lenkkeri U, Kestilä M, Jalanko H, Holmberg C, Tryggvason K (1999) Nephrin is specifically located at the slit diaphragm of glomerular podocytes. Proc Natl Acad Sci USA 96:7962-7967

7. Barletta GM, Kovari I, Verma R, Kerjaschki D, Holzman L (2003) Nephrin and Neph1 co-localize at the podocyte foot process intercellular junction and form cis hetero-oligomers. J Biol Chem 278:19266-19271

8. Pätari-Sampo A, Ihalmo P, Holthöfer H (2006) Molecular basis of the glomerular filtration: nephrin and the emerging protein complex at the podocyte slit diaphragm. Ann Med 38:483-492

9. Benzing T (2004) Signalling in the slit diaphragm. Am J Soc Nephrol 15:1382-1391 
10. Kestilä M, Lenkkeri U, Männikkö M, Lamrdin J, McCready P, Putaala H, Ruotsalainen V, Morita T, Nissinen M, Herva R, Kashtan C, Peltonen L, Holmberg C, Olsen A, Tryggvason K (1998) Positionally cloned gene for a novel glomerular proteinnephrin - is mutated in congenital nephrotic syndrome. Mol Cell $1: 575-582$

11. Koziell A, Grech V, Hussain S, Lee G, Lenkkeri U, Tryggvson K, Scambler P (2002) Genotype/phenotype correlations of NPHS1 and NPHS2 mutations in nephrotic syndrome advocate a functional inter-relationship in glomerular filtration. Hum Mol Genet 11:379-388

12. Beltcheva OJ, Martin P, Lenkkeri U, Tryggvason K (2001) Mutation spectrum in the nephrin gene (NPHS1) in congenital nephrotic syndrome. Hum Mutat 17:368-373

13. Gigante M, Monno F, Roberto R, Laforgia N, Assael M, Livolti S, Caringella A, La Manna A, Masella L, Iolascon A (2002) Congenital nephrotic syndrome of the Finnish type in Italy; A molecular approach. J Nephrol 15:696-702

14. Patrakka J, Kestilä M, Wartiovaara J, Ruotsalainen V, Tissari P, Lenkkeri U, Männikkö M, Vispää I, Holmberg C, Rapola J, Tryggvason K, Jalanko H (2000) Congenital nephrotic syndrome (NPHS1): Features resulting from different mutations in Finnish patients. Kidney Int 58:972-980

15. Boute N, Gribouval O, Roselli S, Benessy F, Lee H, Fuchshuber A, Dahan K, Gubler M, Niaudet P, Antignac C (2000) NPHS2, encoding the glomerular protein podocin, is mutated in autosomal recessive steroid-resistant nephrotic syndrome. Nat Genet 24:349354

16. Caridi G, Perfumo F, Ghiggeri G (2005) NPHS2 (Podocin) mutations in nephrotic syndrome. Clinical spectrum and fine mechanisms. Pediatr Res 57:54R-61R

17. Hinkes B, Mucha B, Vlangos C, Gbadegesin R, Liu J, Hasselbacher K, Hangan D, Ozaltin F, Zenker M, Hildebrandt F; Arbeitsgemeinschaft fur Paediatrische Nephrologie Study Group (2007) Nephrotic syndrome in the first year of life: two thirds of cases are caused by mutations in 4 genes (NPHS1, NPHS2, WT1, LAMB2). Pediatrics 119:e907-e919

18. Nishibori Y, Liu L, Hosoyamada M, Endou H, Kudo A, Takenaka H, Higashihara E, Bessho F, Takasashi S, Kershaw D, Ruotsalainen V, Tryggvason K, Khoshnoodi J, Yan K (2004) Diseasecausing missense mutations in NPHS2 gene alter normal nephrin trafficking to the plasma membrane. Kidney Int 66:1755-1765

19. Schultheiss M, Ruf R, Mucha B, Wiggins R, Fuchshuber A, Lichtenberger A, Hildebrandt F (2004) No evidence for genotype/ phenotype correlation in NPHS1 and NPHS2 mutations. Pediatr Nephrol 19:1340-1348

20. Coppes MJ, Huff V, Pelletier J (1993) Denys-Drash syndrome: Relating a clinical disorder to genetic alterations in the tumor suppressor gene WT1. J Pediatr 123:673-678

21. Mrowka C, Schedl A (2000) Wilms' tumor suppressor gene WT1: From structure to renal pathophysiologic features. J Am Soc Nephrol 11:S106-S115

22. Schumacher V, Scharer K, Wuhl E, Altrogge H, Bonzel K, Guschmann M, Neuhaus T, Pollastro R, Kuwertz-Broking E, Bulla M, Tondera A, Mundel P, Helmchen U, Waldherr R, Weirich A, Royer-Bokora B (1998) Spectrum of early onset nephrotic syndrome associated with WT1 missense mutations. Kidney Int 53:1594-1600

23. Jeanpierre C, Denamur E, Henry I, Cabanis M, Luce S, Cecille A, Elion J, Peuchmaur M, Loirat C, Niaudet P, Gubler M, Junien C (1998) Identification of constitutional WT1 mutations in patients with isolated diffuse mesangial sclerosis, and analysis of genotype/phenotype correlations by use of computerized mutation database. Am J Hum Genet 62:824-833

24. Zenker M, Aigner T, Wendler O, Tralau T, Munteferring H, Fenski R, Pitz S, Schumacher V, Royer-Pokora B, Wuhl E, Cochat P, Bouvier
R, Kraus C, Mark K, Madlon H, Dotsch J, Rascher W, MaruniakChudek I, Lennert T, Neumann L, Reis A (2004) Human laminin B2 deficiency causes congenital nephrosis with mesangial sclerosis and distinct eye abnormalities. Hum Mol Genet 13:2625-2632

25. Hasselbacher K, Wiggins R, Metejas V, Hinkes B, Mucha B, Hoskins B, Ozaltin F, Nurnberg G, Becker C, Hangan D, Pohl M, KuwertzBroking E, Griebel M, Schumacher V, Royer-Pokora B, Bakkaloglu A, Nurnberg P, Zenker M, Hildebrandt F (2006) Recessive missense mutations in LAMB2 expand the clinical spectrum of LAMB2associated disorders. Kidney Int 70:1008-1012

26. Galloway WH, Mowat AP (1968) Congenital microcephaly with hiatus hernia and nephrotic syndrome in two sibs. J Med Genet $5: 319-321$

27. Goldenberg A, Ngoc L, Thouret M, Cormier-Daire V, Gagnadoux M, Chretien D, Lefrancois C, Geromel V, Rötig A, Rustin P, Munnich A, Paquis V, Antignac C, Gubler M, Niaudet P, de Lonlay P, Berard E (2005) Respiratory chain deficiency presenting as congenital nephrotic syndrome. Pediatr Nephrol 20:465-469

28. Bongers E, Gubler M, Knoers N (2002) Nail-patella syndrome. Overview on clinical and molecular findings. Pediatr Nephrol 17:703-712

29. van der Knaap M, Wevers R, Monnens L, Jakobs C, Jaeken J, van Wijik J (1996) Congenital nephrotic syndrome: a novel phenotype of type I carbohydrate-deficient glycoprotein syndrome. J Inherit Metab Dis 19:787-791

30. Hata D, Miyazaki M, Seto S, Kadota E, Muso E, Takasu K, Nakano A, Tamai K, Uitto J, Nagata M, Moriyama K, Miyazaki K (2005) Nephrotic syndrome and aberrant expression of laminin isoforms in glomerular basement membranes for an infant with Herlitz junctional epidemolysis bullosa. Pediatrics 116:e601-607

31. Hinkes B, Wiggins R, Gbadegesin R, Vlangos CN, Seelow D, Nürnberg G, Garg P, Verma R, Chaib H, Hoskins BE, Ashraf S, Becker C, Hennies HC, Goyal M, Wharram BL, Schachter AD, Mudumana S, Drummond I, Kerjaschki D, Waldherr R, Dietrich A, Ozaltin F, Bakkaloglu A, Cleper R, Basel-Vanagaite L, Pohl M, Griebel M, Tsygin AN, Soylu A, Müller D, Sorli CS, Bunney TD, Katan M, Liu J, Attanasio M, O'toole JF, Hasselbacher K, Mucha B, Otto EA, Airik R, Kispert A, Kelley GG, Smrcka AV, Gudermann T, Holzman LB, Nürnberg P, Hildebrandt F (2006) Positional cloning uncovers mutations in PLCE1 responsible for a nephrotic syndrome variant that may be reversible. Nat Genet 38:1397-1405

32. Vachvanishsanong P, Mitarnum W, Tungsinmunkong K, Disseneewate P (2005) Congenital and infantile nephrotic syndrome in Thai infants. Clin Pediatr 44:169-174

33. Besbas N, Bayrakci U, Kale G, Cenzig A, Ackoren Z, Akinci D, Kilic I, Bakkaloglu A (2006) Cytomegalovirus-related congenital nephrotic syndrome with diffuse mesangial sclerosis. Pediatr Nephrol 21:740-742

34. Debiec H, Nauta J, Coulet F, van der Burg M, Guiqonis V, Schurmans T, de Heer E, Soubrier F, Janssen F, Ronco P (2004) Role of truncating mutations in MME gene in fetomaternal alloimmunisation and antenatal glomerulopathies. Lancet 364:1194-1196

35. Patrakka J, Martin P, Salonen R, Kestilä M, Ruotsalaiunen V, Männikkö M, Ryynänen M, Rapola J, Holmberg C, Tryggvason K, Jalanko H (2002) Proteinuria and prenatal diagnosis of congenital nephrosis in fetal carriers of nephrin gene mutations. Lancet 359:1575-1577

36. Licht C, Eifinger F, Gharib M, Offner G, Michalk D, Querfeld U (2000) A stepwise approach to treatment of early onset nephrotic syndrome. Pediatr Nephrol 14:1077-1082

37. Kovacevic L, Reid C, Ridgen S (2003) Management of congenital nephrotic syndrome. Pediatr Nephrol 18:426-430 
38. Salvatierra O, Sarwal M (2000) Renal perfusion in infant recipients of adult sized kidneys is critical risk factor. Transplantation 70:412-413

39. Kuusniemi A-M, Qvist E, Sun Y, Patrakka J, Rönnholm K, Karikoski R, Jalanko H (2007) Plasma exchange and retransplantation in recurrent nephrosis of patients with congenital nephrotic syndrome of the Finnish type. Transplantation 83:1316-1323

40. Qvist E, Laine J, Rönnholm K, Jalanko H, Leijala M, Holmberg C (1999) Graft function 5-7 years after renal transplantation in early childhood. Transplantation 67:1043-1049

41. Benfield M, McDonald R, Bartosh S, Ho P, Harmon W (2003) Changing trends in pediatric transplantation: 2001 Annual Report of the North American Pediatric Renal Transplant Cooperative study. Pediatr Transplant 7:321-331

\section{Answers:}

1. $\mathrm{b}$

2. c

3. a

4. b

5. c 